\title{
A Comparison of the Results of Bacteriological Examination of a Sputum Collection and a Pair of Laryngeal Swab Specimens in Patients Receiv- ing Chemotherapy for Pulmonary Tuberculosis*
}

\author{
By \\ S. Velu, A. S. L. Narayana and T. V. Subbaiah
}

\begin{abstract}
The accurate evaluation of the progress of patients undergoing treatment for pulmonary tuberculosis is of prime importance. The most valuable assessment of a treatment is its effect on the bacterial population of the sputum. A reduction in the number of organisms being excreted, or their complete elimination, is the best evidence that the patient is responding to treatment, and bacteriological negativity is the crucial desideratum of the quiescence of the disease (American Trudeau Society, 1959; Devadatta et al., 1961). In a previous report from this Centre (Andrews and Radhakrishna, 1959) a comparison was made of the results of smear and culture examinations of specimens of sputum obtained in 2 different ways from patients receiving chemotherapy. It was found that "spot" specimens, that is, specimens produced in the Centre within the course of a few minutes were less frequently positive than "collection" specimens, that is, specimens produced overnight in the home.
\end{abstract}

During treatment and usually within a few months of the start of effective chemotherapy, the majority of patients find it difficult to expectorate and it, therefore, becomes of interest to study the relative usefulness of collection specimens of sputum and laryngeal swabs in detecting the presence of tubercle bacilli. This report presents the results of a comparison of an overnight collection specimen of sputum (referred to as sputum specimen in the rest of the report) with a pair of laryngeal swabs (considered as a single specimen in the laboratory) taken from patients during the third to twelfth month of anti-tuberculosis chemotherapy.

\section{MATERIAL}

The specimens analysed were taken from the 315 patients who were treated at home for a period of 1 year in a controlled clinical study of 4 different regimens of chemotherapy (Tuberculosis Chemotherapy Centre, Madras, 1960). One of the regimens studied was a combination of isoniazid and PAS, and the other 3 were regimens of isoniazid alone. Laryngeal swab specimens were taken at the completion of 3 months of treatment and at monthly intervals thereafter; consequently, 7 patients who had died before completing 3 months of treatment and 2 who had had their chemotherapy changed due to early drug toxicity do not appear in the present analysis. There remain 306 patients who were due to have 2 collection specimens of sputum and a pair of laryngeal swabs, at monthly intervals from the third month onwards. (Patients who died are excluded after their death and patients who had their chemotherapy changed, either due to deterioration of their disease or due to drug toxicity, are excluded after the change.)

- From the Tuberculosis Chemotherapy Centre, Madras, India. The Centre is under the joint auspices of the Indian Council of Medical Research, the Madras State Government, the World Health Organisation and the Medical Research Council of Great Britain. 
All the patients admitted to the controlled study were Indians who were residents of Madras City, and had bacteriologically confirmed pulmonary tuberculosis. The great majority, namely, 295 (96.4 \%) had had no anti-tuberculosis chemotherapy before admission to the study and the remaining 11 (3.6\%) had had less than 2 weeks of chemotherapy. Of the 306 patients, $63.4 \%$ were males and $95.1 \%$ were between 15 and 54 years of age. All had radiographic appearances compatible with pulmonary tuberculosis; $246(80.4 \%)$ had bilateral disease, $245(80.0 \%)$ had 3 or more lung zones involved in disease, $208(68.0 \%)$ had moderate, extensive or gross lesions (for definition see Tuberculosis Chemotherapy Centre, Madras, 1960) and 284 (92.8\%) had obvious cavitation on a postero-anterior radiograph; the disease was confined to 1 lung zone only in $10(3.3 \%)$ of the patients.

\section{Bacteriological Investigations}

Each patient produced 2 collection specimens of sputum at the end of each month of treatment and, in addition, from 3 months onwards a pair of laryngeal swab specimens was taken at the Centre on the day of each monthly examination up to the end of 12 months. This was done because at this point in their treatment patients began to have difficulty in expectorating. The sputum specimens were examined for the presence of tubercle bacilli both by smear and culture and the laryngeal swab only by culture. In the present report the results of the first, and in some instances the only, sputum specimen at each month from three months onwards have been compared with the results of the corresponding pairs of laryngeal swabs, each pair being considered as a single specimen.

\section{Methods of Obtaining Specimens}

(a) Collection specimens of sputum: At the end of each month of treatment the patient was given a sterile numbered screw-capped McCartney bottle, either on attending the morning out-patient clinic or by a health visitor at his home (usually in the morning) and was instructed to expectorate into it until it was nearly full. The following morning the bottle was brought to the Centre by the patient, or collected by a health visitor and handed in at the laboratory. The specimen was, thus, material collected overnight and sometimes covered a period of upto 24 hours. The procedure was to collect 2 such specimens during the 48 hours prior to each monthly examination.

(b) Laryngeal swab specimens: Each swab was made of a 9-12" length of malleable stainless steel wire of $2 \mathrm{~mm}$ diameter to one end of which was wound a pledget of absorbent cotton wool and the other end made into a full loop of $1 / 2$ " diameter. It was suspended in a test tube and a ball of non-absorbent cotton, rolled in a piece of gauze inserted between the 2 ends of the wire, served as a plug. The tubes were sterilised in a hot air oven at about $160^{\circ} \mathrm{C}$ for 90 minutes.

To obtain a specimen the sterile swab was removed from the test tube and the cotton-covered end was dipped in sterile distilled water. The wire was then bent with a pair of sterile pliers through an angle of about $45^{\circ}$ at a point $2 "$ from the pledget end. The patient was asked to extrude his tongue, hold it himself with a sterile piece of gauze, and to say "Ah"; the end of the swab was then introduced blindly into the larynx. If this procedure did not initiate a cough, the patient was asked to cough several times while the swab was in the hypopharynx. In the case of children the mother held the child firmly whilst the tongue was depressed with a wooden spatula and the swab inserted into the back of the throat. A slight tickling of the throat with the swab produced a cough even in very young infants. The swab was removed and straightened with sterile pliers and resuspended in the test tube. A pair of swabs was obtained in the Centre from each patient on the day of the monthly examination. They were delivered to the laboratory within a matter of minutes and processed the same morning. Each

Ind. J. Tub., Vol. VIII, No 4 . 
pair was considered as 1 specimen. The great majority of swabs was taken by the Centre's doctors and the remainder by experienced public health nurses.

\section{Bacteriological Procedures}

(a) Examination of the sputum: Each specimen of sputum was examined by the following techniques:

(i) Fluorescence microscopy of direct smear: A new glass slide was used for the preparation of each smear. Purulent, or failing this, mucoid material or any deposit in the sputum, was selected for examination. The method of fluorescence microscopy used in this laboratory has been described by Holst et al. (1959) who found practically no difference between the results of the standard Ziehl-Neelsen technique and of fluorescence microscopy in the detection of tubercle bacilli. Positive smears were graded as 3-plus, 2-plus, or 1-plus, according to the average number of bacilli seen per field (Tuberculosis Chemotherapy Centre, Madras, 1959).

(ii) Culture: In brief, the sputum specimens were treated with $4 \%$ sodium hydroxide for 30 minutes and the centrifuged deposit was washed with sterile distilled water by successive centrifugation in order to dilute the concentrate and thus prevent the carry over of anti-tuberculosis drugs to the culture medium. The centrifuged deposit was inoculated onto 2 slopes of Löwenstein-Jensen medium without potato starch (Jensen, 1955). Cultures were examined weekly for between 8 and 9 weeks and were reported as negative only if no growth was present by the end of that time. Growth typical of M yco. tuberculosis was graded when it was first seen as 3-plus if it was confluent, 2-plus if there were innumerable discrete colonies, 1-plus if there were 100 to 20 colonies, and the number of colonies was recorded if this was less than 20.

(b) Culture of laryngeal swabs: The 2 laryngeal swabs taken from each patient were decontaminated in $4 \%$ sulphuric acid for 10 minutes and then neutralized by immersion in $1 \%$ sodium hydroxide for 1 minute. Each swab was then rubbed on to the surface of one slope of Löwenstein-Jensen medium. The slopes were incubated and reported on in the same way as the sputum cultures. The cultures were read once weekly and the reader was unaware of the origin of any of them.

\section{RESULTS}

Separate analyses (not tabulated here) revealed that the comparison of sputum and laryngeal swabs led to similar conclusions in each of the 4 treatment regimens. Consequently, the results in the 4 treatment series have been amalgamated and, for convenience in presentation, the months of treatment have been grouped in pairs.

\section{Comparison of Sputum Smears and Laryngeal Swab Cultures}

Table 1 compares the results of smear examination of sputum specimens with culture examination of laryngeal swab specimens. After 3 and 4 months of chemotherapy, $16.4 \%$ of the patients were positive both on sputum smear and on laryngeal swab culture and $71.8 \%$ were negative on both. The proportion of patients negative on sputum smear but positive on laryngeal swab culture was $3.9 \%$, compared with $7.8 \%$ of patients who were negative on laryngeal swab culture but positive on sputum smear. However, to eliminate the possibility that this $7.8 \%$ is an overestimate due to the inclusion of patients excreting non-viable bacilli, i.e. patients who had a positive sputum smear but negative culture, a fresh analysis was done in which smear-positive, culturenegative results were regarded as smear-negative for the purpose of this comparison. The proportion of specimens which yielded a positive result both on sputum smear and sputum culture and a negative result on laryngeal swab culture was found to be $6.3 \%$. 
TABLE 1

Results of Smear Examination of Sputum Specimens and Culture Examination of a Pair of Laryngeal Swab Specimens

\begin{tabular}{|c|c|c|c|c|}
\hline $\begin{array}{l}\text { Months after } \\
\text { start of } \\
\text { chemotherapy }\end{array}$ & $\begin{array}{l}\text { Sputum specimen } \\
\text { (result of smear } \\
\text { examination) }\end{array}$ & $\begin{array}{l}\text { Laryngeal swab } \\
\text { specimen (result of } \\
\text { culture examination) }\end{array}$ & $\begin{array}{l}\text { Number of } \\
\text { patients }\end{array}$ & $\begin{array}{l}\text { Percentage of } \\
\text { patients }\end{array}$ \\
\hline \multirow{4}{*}{$3 \& 4$} & Negative & Negative & 421 & 71.8 \\
\hline & Negative & Positive & 23 & 3.9 \\
\hline & Positive & Negative & 46 & $7.8(6.3) *$ \\
\hline & Positive & Positive & 96 & 16.4 \\
\hline \multirow{4}{*}{$5 \& 6$} & Negative & Negative & 431 & 73.9 \\
\hline & Negative & Positive & 19 & 3.3 \\
\hline & Positive & Negative & 35 & $6.0(4.1) *$ \\
\hline & Positive & Positive & 98 & 16.8 \\
\hline \multirow{4}{*}{$7 \& 8$} & Negative & Negative & 430 & 77.6 \\
\hline & Negative & Positive & 19 & 3.4 \\
\hline & Positive & Negative & 20 & $3.6(3.6) *$ \\
\hline & Positive & Positive & 85 & 15.3 \\
\hline \multirow{4}{*}{$9 \& 10$} & Negative & Negative & 423 & 79.2 \\
\hline & Negative & Positive & 23 & 4.3 \\
\hline & Positive & Negative & 16 & $3.0(2.4) *$ \\
\hline & Positive & Positive & 12 & 13.5 \\
\hline \multirow{4}{*}{$11 \& 12$} & Negative & Negative & 416 & 82.1 \\
\hline & Negative & Positive & 19 & 3.7 \\
\hline & Positive & Negative & 15 & $3.0(3.0) *$ \\
\hline & Positive & Positive & 57 & 11.2 \\
\hline
\end{tabular}

*Regarding patients with a positive sputum smear but a negative sputum culture (i.e., patients who yielded non-viable bacilli) as negative on smear examination.

Thus, smear examinations of the sputum yielded more genuine positive results at 3 and 4 months than culture examinations of laryngeal swabs. At 5 and 6 months, there was still a suggestion that the sputum smears were superior. At 7 and 8 months there was hardly any difference, and in the later months of treatment the laryngeal swab cultures yielded slightly more positive results than the sputum smears.

Ind. 3. Tub., Vol. VIM, No. 4. 
TABLE 2

Results of Culture Examination of a Single Sputum and a Pair of Laryngeal Swab Specimens

\begin{tabular}{|c|c|c|c|c|c|c|c|}
\hline \multirow{2}{*}{$\begin{array}{l}\text { Months } \\
\text { after start } \\
\text { of chemo- } \\
\text { therapy }\end{array}$} & \multirow[t]{2}{*}{$\begin{array}{l}\text { Type of } \\
\text { specimen }\end{array}$} & \multirow[t]{2}{*}{\begin{tabular}{|c|} 
Total \\
cultures
\end{tabular}} & $\begin{array}{l}\text { Contamina- } \\
\text { ted cultures }\end{array}$ & \multicolumn{2}{|c|}{$\begin{array}{l}\text { Culture positive, } \\
\text { graded as: }\end{array}$} & \multirow{2}{*}{$\begin{array}{l}\begin{array}{c}\text { Total posi- } \\
\text { tive cultures }\end{array} \\
\text { No. } \%\end{array}$} & $\begin{array}{l}\text { Total nega- } \\
\text { tive cultures }\end{array}$ \\
\hline & & & No. $\%$ & $\begin{array}{l}\text { More } \\
\text { than } 100 \\
\text { colonies }\end{array}$ & $\begin{array}{c}100 \\
\text { colonies } \\
\text { or less }\end{array}$ & & $\mathrm{No} . \%$ \\
\hline \multirow[b]{2}{*}{$3 \& 4$} & Sputum & 601 & 9215.3 & 72 & 117 & 18931.4 & 32053.2 \\
\hline & $\begin{array}{l}\text { Laryngeal } \\
\text { swab }\end{array}$ & 601 & 152.5 & 11 & 108 & 11919.8 & 46777.7 \\
\hline \multirow{2}{*}{$5 \& 6$} & Sputum & 587 & 7913.5 & 69 & 78 & 14725.0 & 36161.5 \\
\hline & $\begin{array}{l}\text { Laryngeal } \\
\text { swab }\end{array}$ & 587 & 40.7 & 20 & 97 & 11719.9 & 46679.4 \\
\hline \multirow{2}{*}{$7 \& 8$} & Sputum & 560 & $57 \quad 10.2$ & 78 & 69 & 14726.2 & 35663.6 \\
\hline & $\begin{array}{l}\text { Laryngeal } \\
\text { swab }\end{array}$ & 560 & 61.1 & 16 & 88 & 10418.6 & $450 \quad 80.4$ \\
\hline \multirow[b]{2}{*}{$9 \& 10$} & Sputum & 546 & 5510.1 & 63 & 56 & 11921.8 & $372 \quad 68.1$ \\
\hline & $\begin{array}{l}\text { Laryngeal } \\
\text { swab }\end{array}$ & 546 & 122.2 & 5 & 90 & $95 \quad 17.4$ & $439 \quad 80.4$ \\
\hline \multirow{2}{*}{$11 \& 12$} & Sputum & 515 & 499.5 & 53 & 46 & 9919.2 & $367 \quad 71.3$ \\
\hline & $\begin{array}{l}\text { Laryngeal } \\
\text { swab }\end{array}$ & 515 & 81.6 & 5 & 71 & 7614.8 & $431 \quad 83.7$ \\
\hline
\end{tabular}

\section{Findings on Culture}

The findings are presented in Table 2 and illustrated graphically in Figure 1. The sputum specimens consistently yielded a greater number of positive results than the laryngeal swabs. The difference was maximal at 3 and 4 months after start of chemotherapy; thus, $189(31.4 \%)$ of 601 sputum cultures were positive compared with 119 $(19.8 \%)$ of the same number of laryngeal swab cultures, the difference attaining statistical significance $(\mathrm{P}<0.001)$. From 5 to 12 months of chemotherapy, the difference between the proportions of positive cultures yielded by the 2 types of specimens was smaller and there was very little change from month to month. After 11 and 12 months of chemotherapy, the proportions were $19.2 \%$ and $14.8 \%$ for sputum and laryngeal swab specimens, respectively (P nearly equals 0.07 ). Growth of more than 100 colonies was much more common with sputum cultures than with laryngeal swab cultures. Thus, at 3 and 4 months, $72(38.1 \%)$ of 189 positive sputum cultures yielded more than 100 colonies, compared with $11(9.2 \%)$ of the 119 laryngeal swab cultures $(\mathrm{P}<0.001)$. At 11 and 12 months the corresponding proportions were $53.5 \%$ and $6.6 \%$ respectively $(\mathrm{P}<0.001)$.

Table 3 gives the result of culture examination of each type of specimen when the result of the culture on the other type of specimen was either negative or contaminated. Of 412 sputum specimens that were negative or contaminated on culture after 3 and 4 months of chemotherapy, $12(2.9 \%)$ yielded a positive result on laryngeal swab 
FIG. 1

PERCENTAGE OF PATIENTS WHO YIELDED A POSITIVE CULTURE AT EACH MONTH

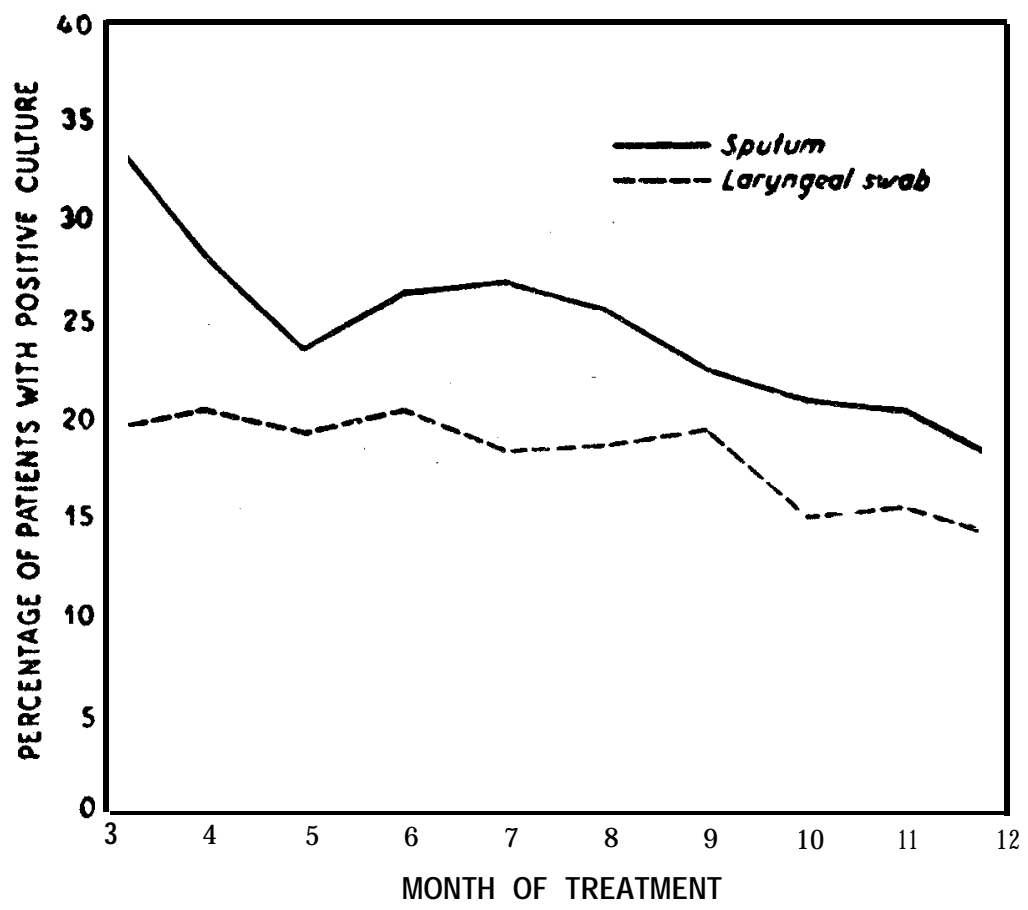

FIG. 2

PERCENTAGE OF PATIENTS WHO YIELDED A CONTAMINATED CULTURE AT EACH MONTH

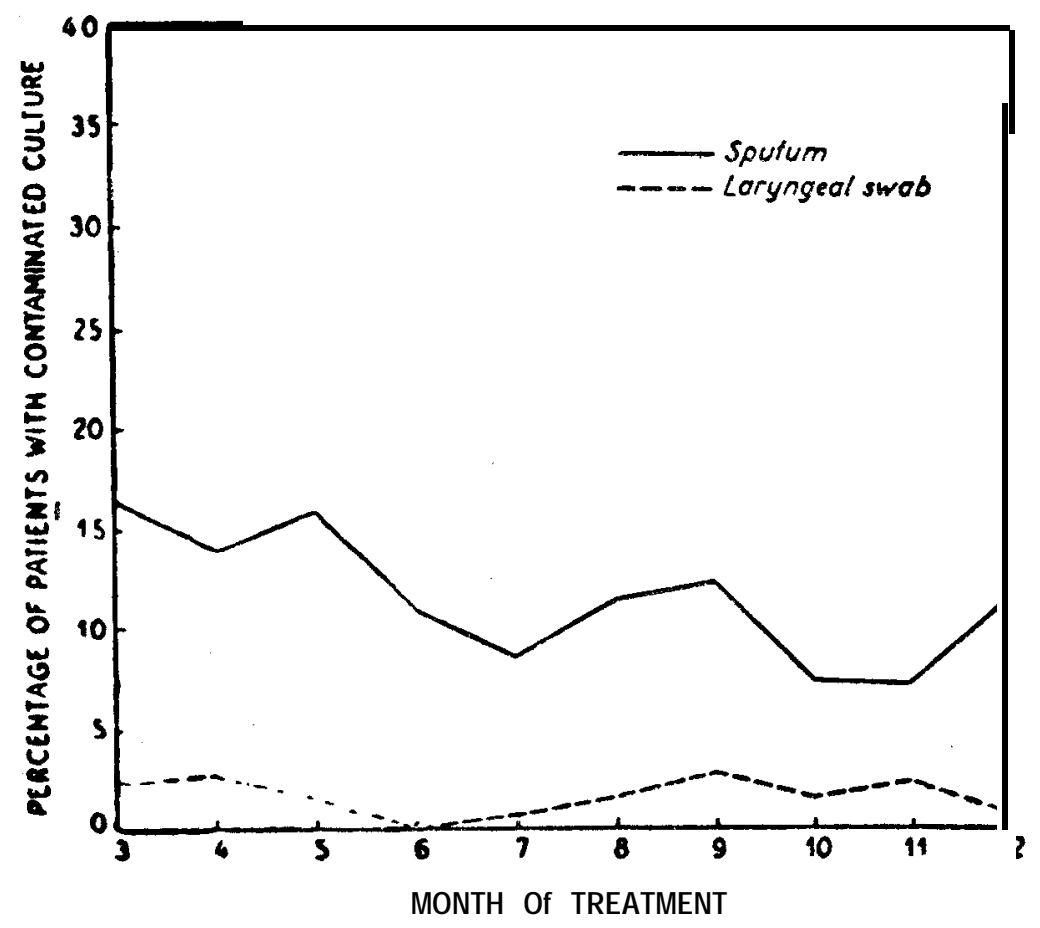


TABLE 3

Result of Culture Examination of one Type of Specimen when the Result of the other Type was Negative or Contaminated

\begin{tabular}{|c|c|c|c|c|c|c|c|c|c|c|}
\hline \multirow{4}{*}{$\begin{array}{l}\text { Months } \\
\text { after start } \\
\text { of chemo- } \\
\text { therapy }\end{array}$} & \multirow{4}{*}{$\begin{array}{l}\text { Type of } \\
\text { specimen }\end{array}$} & \multirow{4}{*}{$\begin{array}{l}\text { Number of } \\
\text { cultures } \\
\text { with a } \\
\text { negative } \\
\text { or conta- } \\
\text { minated } \\
\text { result on } \\
\text { the other } \\
\text { type of } \\
\text { specimen } \\
\end{array}$} & \multicolumn{8}{|c|}{ Result of culture examination } \\
\hline & & & \multirow{2}{*}{\multicolumn{2}{|c|}{$\underset{\text { nated }}{\text { Contami- }}$}} & \multicolumn{2}{|c|}{ Positive, graded as: } & \multirow{2}{*}{\multicolumn{2}{|c|}{$\begin{array}{c}\text { Total } \\
\text { positive }\end{array}$}} & \multirow{2}{*}{\multicolumn{2}{|c|}{$\begin{array}{c}\text { Total } \\
\text { negative }\end{array}$}} \\
\hline & & & & & \multirow{2}{*}{$\begin{array}{l}\text { More } \\
\text { than } 100 \\
\text { colonies }\end{array}$} & \multirow{2}{*}{$\begin{array}{l}100 \text { colo- } \\
\text { nies or } \\
\text { less }\end{array}$} & & & & \\
\hline & & & No. & $\%$ & & & No. & $\%$ & No. & $\%$ \\
\hline \multirow{2}{*}{$3 \& 4$} & $\begin{array}{l}\text { Laryngeal } \\
\text { swab }\end{array}$ & 412 & & 2.7 & 2 & 10 & 12 & 2.9 & 389 & \\
\hline & Sputum & 482 & & 16.8 & 13 & 68 & 81 & 16.8 & 320 & 66.4 \\
\hline \multirow{2}{*}{$5 \& 6$} & $\begin{array}{l}\text { Laryngeal } \\
\text { swab }\end{array}$ & 440 & & 0.5 & 3 & 19 & 22 & & 416 & \\
\hline & Sputum & 470 & 62 & 13.2 & 11 & 41 & 52 & 11.1 & 356 & 75.7 \\
\hline \multirow{2}{*}{$7 \& 8$} & $\begin{array}{l}\text { Laryngeal } \\
\text { swab }\end{array}$ & 413 & & & 1 & 10 & 11 & & 399 & \\
\hline & & 456 & & 11.2 & 13 & 41 & 54 & 11.8 & 351 & 77.0 \\
\hline \multirow{2}{*}{$9 \& 10$} & $\begin{array}{l}\text { Laryngeal } \\
\text { swab }\end{array}$ & 427 & & 2.3 & 1 & 12 & 13 & 3.0 & 404 & 94.6 \\
\hline & Sputim & $\Delta 41$ & $5 n$ & 111 & 12 & 24 & 37 & 82 & 364 & sn. 7 \\
\hline \multirow{2}{*}{$11 \& 12$} & $\begin{array}{l}\text { Laryngeal } \\
\text { swab }\end{array}$ & 416 & & 1.4 & 0 & 9 & 9 & 2.2 & 401 & 96.4 \\
\hline & Sputum & 439 & 44 & 10.0 & 5 & 27 & 32 & 7.3 & 363 & 82.7 \\
\hline
\end{tabular}

culture. Conversely, of 482 cultures which yielded either a negative or a contaminated result on laryngeal swab culture at 3 and 4 months, $81(16.8 \%)$ were positive on sputum culture. This difference attains statistical significance $(\mathrm{P}<0.001)$. The same pattern was present throughout the rest of the year but the differences were smaller.

\section{Frequency of Contaminated Cultures}

Cultures from collection specimens of sputum were contaminated more often than those from laryngeal swabs (Table 2 and Figure 2). Thus, 92 (15.3\%) of 601 cultures from collection sputum specimens obtained at 3 and 4 months after the start of chemotherapy yielded contaminated results, compared with $15(2.5 \%)$ of the same number of laryngeal swab specimens. This difference attains statistical significance $(\mathrm{P}<0.001)$. Similar differences existed at all the subsequent months, the contamination rate for the collection specimens being at least 4 times as large as that for laryngeal swabs. 
TABLE 4

Frequency of Contaminated Cultures in Patients from whom 24 Sputum Specimens were Examined

\begin{tabular}{|c|c|c|}
\hline $\begin{array}{c}\text { Number of } \\
\text { contaminated } \\
\text { cultures }\end{array}$ & $\begin{array}{c}\text { Number of } \\
\text { patients with } \\
\text { contaminated } \\
\text { cultures }\end{array}$ & $\begin{array}{c}\text { Expected number } \\
\text { of patients with } \\
\text { contaminated } \\
\text { cultures@ }\end{array}$ \\
\hline 0 & 18 & 12.32 \\
1 & 38 & 29.22 \\
2 & 24 & 34.65 \\
3 & 20 & 27.39 \\
4 & 13 & 16.24 \\
5 & 4.70 \\
6 & 2 & 3.04 \\
7 & 1 & 1.03 \\
8 & 1 & 0.30 \\
9 & 1 & 0.08 \\
10 & 132 & 0.02 \\
11 or more & 0 & 132.00 \\
\hline Tottal patients & 132 \\
\hline @Based on the hypothesis that contamination is a random \\
phenomenon following a Poisson distribution
\end{tabular}

Two analyses were undertaken, one on the sputum specimens and the other on the laryngeal swab specimens, to determine whether the contamination of cultures occurred at random, or whether some patients were more prone to yield contaminated cultures than others. The first analysis was based on the sub-group of 132 patients who had 24 sputum specimens examined during the year of chemotherapy. The number of contaminated cultures yielded by these patients is shown in Table 4. Of a total of 3,168 cultures examined from the 132 patients, $313(9.9 \%)$ were contaminated giving a mean of 2.37 contaminated cultures per patient. On the hypothesis that contamination is a random phenomenon following the Poisson distribution with a mean of 2.37 the numbers of patients expected to yield $0,1, \ldots 10,11$ or more contaminated cultures were calculated and the findings are presented in the final column of Table 4. It can be seen that, whereas only 12 patients would have been expected to yield 5 or more contaminated cultures, the actual number observed was 19. At the other extreme, 56

TABLE 5

Frequency of Contaminated Cultures in Patients from whom I or more Laryngea. Swab Specimens were Examined

\begin{tabular}{|c|c|c|}
$\begin{array}{c}\text { Number of } \\
\text { contaminated } \\
\text { cultures }\end{array}$ & $\begin{array}{c}\text { Number of } \\
\text { patients with } \\
\text { contaminated } \\
\text { cultures }\end{array}$ & $\begin{array}{c}\text { Expected number } \\
\text { of patients with } \\
\text { contaminated } \\
\text { cultures@ }\end{array}$ \\
\hline $\mathbf{0}$ & $\mathbf{2 6 7}$ & $\mathbf{2 6 2 . 4 3}$ \\
$\mathbf{1}$ & $\mathbf{3 3}$ & $\mathbf{4 0 . 3 0}$ \\
$\mathbf{3}$ & $\mathbf{4}$ & 0.15 \\
$\mathbf{3}$ or more & $\mathbf{2}$ & 0.03 \\
\hline Total patients & $\mathbf{0}$ & 306.00 \\
\hline
\end{tabular}

@Based on the hypothesis that contamination is a random phenomenon following a Poisson distribution

patients yielded either 1 contaminated culture or none, compared with an expected number of 42 . The difference between the expected distribution and the observed distribution is statistically significant at the $1 \%$ level. A similar analysis (not tabulated 
here) of another 76 patients from each of whom 23 collection specimens were examined yielded similar results. It may be concluded that some patients yielded contaminated cultures on sputum specimens more often than would have been expected purely by chance. On the other hand, there was no evidence from the analysis on the laryngeal swab cultures that contamination was not a random phenomenon following the Poisson distribution. This can be seen from the fact that the observed and expected frequencies were closely similar (Table 5).

\section{Practical Applications of the Findings.}

In order to relate the findings to different practical situations, for example, the availability of culture facilities or the ability to obtain more than 1 type of specimen from the patient, an analysis was undertaken to determine the proportion of occasions when a positive result was yielded by examination of (a) sputum by smear, (b) sputum by culture, (c) laryngeal swab by culture, (d) laryngeal swab by culture and sputum by smear, and finally, (e) laryngeal swab by culture and sputum by culture. Of the total number of occasions when both a sputum smear and a pair of laryngeal swabs by culture were examined, it was found that if the results of sputum smear examination alone were taken into account, the number of positives yielded would have been $145(24.1 \%)$ at 3 and 4 months, $133(22.7 \%)$ at 3 and 6 months, $105(18.8 \%)$ at 7 and 8 months, $90(16.5 \%)$ at 9 and 10 months and $74(14.4 \%)$ at 11 and 12 months. However, the proportions reported in Table 6 are different since a positive result on sputum smear has been accepted as positive only if the sputum culture was positive also. In other words, the positive sputum smears that gave a negative result on sputum culture have been regarded as. negative findings because it was felt that they represented non-viable bacilli. (The smear-positive but culture-contaminated results have been divided as positive or negative

TABLE 6

Positive Findings with Various Combinations of Sputum Specimens and a Pair of Laryngeal Swab Specimens in the Detection of Tubercle Bacilli

\begin{tabular}{|c|c|c|c|c|c|c|c|c|c|c|c|}
\hline \multirow{3}{*}{$\begin{array}{l}\text { Months } \\
\text { after start } \\
\text { of chemo- } \\
\text { therapy }\end{array}$} & \multirow{3}{*}{$\begin{array}{l}\text { Total number } \\
\text { of occasions } \\
\text { when sputum } \\
\text { and laryngeal } \\
\text { swab were } \\
\text { examined }\end{array}$} & \multicolumn{10}{|c|}{ Positive finding with: } \\
\hline & & \multicolumn{2}{|c|}{$\begin{array}{l}\text { Laryngeal } \\
\text { swab culture }\end{array}$} & \multicolumn{2}{|c|}{$\begin{array}{l}\text { Sputum } \\
\text { smear }\end{array}$} & \multicolumn{2}{|c|}{$\begin{array}{r}\text { Laryngeal } \\
\text { swab culture } \\
\text { and sputum } \\
\text { smear@ }\end{array}$} & \multicolumn{2}{|c|}{$\begin{array}{l}\text { Sputum } \\
\text { culture }\end{array}$} & \multicolumn{2}{|c|}{$\begin{array}{c}\text { Laryngeal } \\
\text { swab culture } \\
\text { and sputum } \\
\text { culture@ }\end{array}$} \\
\hline & & No. & $\%$ & No. & $\%$ & No: & $\%$ & No. & $\%$ & No. & $\%$ \\
\hline $3 \& 4$ & 601 & 119 & 19.8 & 133 & 22.1 & 158 & 26.3 & 189 & 31.4 & 216 & 35.9 \\
\hline $5 \& 6$ & 587 & 117 & 19.9 & 123 & 21.0 & 138 & 23.5 & 147 & 25.0 & 177 & 30.2 \\
\hline $7 \& 8$ & 560 & 104 & 18.6 & 104 & 18.6 & 124 & 22.1 & 147 & 26.2 & 165 & 29.5 \\
\hline $9 \& 10$ & 546 & 95 & 17.4 & 84 & 15.4 & 108 & 19.8 & 119 & 21.8 & 137 & 25.1 \\
\hline $11 \& 12$ & 515 & 76 & 14.8 & 71 & 13.8 & 90 & 17.5 & 99 & 19.2 & 112 & 21.7 \\
\hline $\begin{array}{r}\text { All } \\
\text { months }\end{array}$ & 2809 & 511 & 18.2 & 515 & 18.3 & 618 & 22.0 & 701 & 25.0 & 807 & 28.7 \\
\hline
\end{tabular}

@Even if only one of them was positive.

findings in the same proportion in which smear-positive culture-positive and smearpositive culture-negative findings were known to occur.) On 601 occasions at 3 and 4 months when both sputum and laryngeal swab specimens were examined, the laryngeal

Ind. J. Tub., Vol. VIII, No. 4. 
swab culture yielded a positive finding on $119(19.8 \%)$ occasions. The corresponding proportion was $22.1 \%$ with sputum smear, $26.3 \%$ with laryngeal swab culture and sputum smear, $31.4 \%$ with sputum culture and $35.9 \%$ with laryngeal swab culture and sputum culture. The pattern was broadly similar in subsequent months, although from 9 to 12 months, the laryngeal swab cultures were superior to the sputum smears. It may be concluded that sputum culture was the best single examination and that the examination of sputum by smear was, on balance, almost as valuable as the culture of a pair of laryngeal swabs.

\section{DISCUSSION}

It has been found in the present study that from 3 months after start of chemotherapy, the examination by culture of a sputum specimen collected over a period of at least several hours in the home more often yielded a positive result than the examination by culture of a corresponding pair of laryngeal swab specimens, regarded as a single specimen. Furthermore, it was found that even the examination of smears prepared from the collection specimens of sputum compared favourably with the laryngeal swab cultures. Between 3 and 8 months the smears actually yielded more positive findings, although in the later months they yielded less. It must be stressed that all the laryngeal swab specimens were obtained by staff members experienced in the technique of collecting them and that, in this Centre, it is not uncommon to obtain positive cultures from laryngeal swab specimens even in infants and very young children suffering from primary tuberculosis, which is good evidence of the staff's efficiency with the technique. The question, therefore, arises whether laryngeal swab culture, as performed in this Centre, has any place in the management of patients receiving chemotherapy.

The advantages of a laryngeal swab culture compared with culture of a collection specimen of sputum are, first, that it requires only 1 attendance at the clinic; secondly, the laboratory procedures are more simple than for the usual method of sputum culture, which basically requires a centrifuge. Thirdly, there can be no doubt that the specimen has been obtained from the patient and not from some other persons with disease, an important point in controlled clinical studies. Fourthly, in this study, it has been found that the contamination rate is lower with laryngeal swab specimens than with sputum cultures and also that contamination is a random phenomenon in the former whereas it is not so in the latter. On the other hand, however, despite the lower contamination rate, fewer positive results have been obtained with laryngeal swabs than with cultures of sputum.

The advantages of a laryngeal swab culture over a smear from a collection specimen of sputum are, first, that it requires only one attendance at the clinic; secondly, there is no doubt that the specimen has been obtained from the patient; thirdly, the question of whether the bacilli are viable or not does not arise as in the case of a smear examination, and fourthly, drug sensitivity tests and if need be, identification tests can be performed. On the other hand, the laryngeal swab culture which has not yielded, on balance, more positive results requires much more complicated laboratory facilities than are needed for the examination of sputum smears.

The disadvantages of a laryngeal swab over a sputum collection are, first, that the quantity of sputum obtained from the swab would be meagre compared to the collection specimen, thus diminishing the chances of obtaining a positive result. This may be a real handicap especially in the later months of treatment of patients receiving effective chemotherapy. The laryngeal swabs would be pre-eminently suitable and extremely time-saving both for the patient and the medical staff in the early diagnosis of active pulmonary tuberculosis. Secondly, the risk to the clinic staff who actually obtain the 
laryngeal swabs from the patients cannot be overlooked. Thirdly, there is a small additional administrative responsibility in finding separate accommodation for the collection of such specimens and finally, the preparation of the swabs before and after use requires extra staff and sterilizing facilities.

The high rate of contamination with collection specimens of sputum $(10.4 \%)$ in this study was similar to that encountered for all the collection specimens examined at this Centre $(9.5 \%)$ in 1958-59, the period during which this study was undertaken. During the same period the contamination rates for "spot" specimens of sputum (i.e. specimens produced in the clinic within a few minutes) and laryngeal swabs were $2.5 \%$ and $2.3 \%$ respectively. Since the "spot" specimens of sputum were processed in an identical manner to collection specimens, this marked difference between their contamination rates suggests that the majority of the contaminating organisms were present in the collection specimens when they were received in the laboratory and that they did not gain entrance to the specimen during the processing of the sputum. In order to check on the sterility of the medium a sample of 10 slopes from most of the batches used in this study was tested for sterility by incubation at $37^{\circ} \mathrm{C}$ for 15 days. Of 1,520 slopes tested for sterility only $16(1 \%)$ were contaminated. Since two slopes of medium were inoculated from each specimen, contamination of the medium would have been responsible for a contaminated culture result only once in every 10,000 cultures.

The contamination rate of the collection specimens of sputum was at least four times as high as that of the laryngeal swab specimens. An analysis showed that contamination did not occur as a random phenomenon amongst all the sputum specimens but that there was a tendency for it to occur more often in some of the patients. This suggests that the specimens were probably being contaminated by some patients as a result of the -way they were collecting them or else that some patients were harbouring contaminants in their respiratory tracts. Thus, it is possible that some patients were careless in the way they handled the sterile McCartney bottles when producing the specimens and that, despite instructions to the contrary, they left the tops unscrewed and, perhaps, deposited them on dirty surfaces, for example, on the ground. Some patients took a longer time to collect the requisite amount of sputum than others and this undoubtedly was more conducive to contamination. It is of interest that the sputum specimens in the Madras community are sometimes mixed with betel leaf and spiced betel or areca nut, which are commonly chewed with or without tobacco, or with particles of red brick, dung cake ash or half burnt firewood which are used to clean the teeth. No special record was kept of the presence of such material in the specimens so that it is not possible to decide whether such adventitious material in the sputum led to contamination of the cultures. It is also possible that the contamination resulted from the presence of contaminants in the patient's upper respiratory tract as it is common practice both in patients and healthy people to withdraw their nasal secretions into the oral cavity and then spit after clearing the throat.

In this study "spot" specimens, that is, specimens produced on demand and within a matter of a few minutes in the Centre, were not available for comparison with laryngeal swab specimens. It would be valuable to have such a comparison since both "spot" and laryngeal swab specimens require only one attendance at the Centre and, provided the patients expectorate under supervision, it is possible to be sure that the specimen has, in fact, been produced by the patient. A comparison between spot specimens and laryngeal swabs is being undertaken at this Centre. There is also evidence from unpublished data in this Centre that cultures of spot specimens are less frequently contaminated than those from collection specimens.

In a previous study from the Centre (Andrews and Radhakrishna, 1959) it was shown that collection specimens more frequently yielded positive results on smear and 
on culture than spot specimens produced in the Centre. The present study has shown that, as far as positivity is concerned, the examination of collection specimens by smear is as valuable as the culture of laryngeal swab specimens in patients receiving chemotherapy and that the examination of sputum by culture is more valuable than either The findings suggest that an efficient smear service is as adequate as a laryngeal swab culture service in assessing the bacteriological positivity of patients during anti-tuberculosis chemotherapy.

\section{SUMMARY}

1. A comparison is presented between the results of examinations of collection specimens of sputum by smear and by culture with that of laryngeal swab specimens by culture only in patients with bacteriologically confirmed pulmonary tuberculosis from 3 to 12 months after start of anti-tuberculosis chemotherapy. The smears were examined by fluorescence microscopy and cultures were set up on Löwenstein-Jensen medium.

2. The smear examination of the sputum yielded similar proportions of positive findings to the laryngeal swab cultures. Sputum cultures yielded the greatest number of positive results. The relative merits of the three methods of examination have been discussed.

3. Contamination of sputum cultures was more common than contamination of laryngeal swab cultures. The possible explanations for this finding have been discussed.

\section{ACKNOWLEDGEMENT}

The authors wish to acknowledge the work of the entire staff of the Centre, especially the laboratory and clinic staff whose efforts have been largely responsible for the completeness of the data.

\section{ReFerences}

American Trudea Society (1959) Am. Rev. Resp. Dir., 80, 118.

Andrews, R. H. and Radhakrishnan, S. (1959) Tubercle (Lond.), 40, 155.

Devadatta, S., Andrews, R. H, Angel, J. H., Bhatia, A. L., Fox, W., Janardhanam, B., Radhakrishna, S., Ramakrishnan, C. V., Subbaiah, T. V. and Velu, S. (1961) Bull. WId. HIth. Org., 24, 149.

Holst, E., Mitchison, D. A. and Radhakrishna, S. (1959) Indian J. M ed: Res., 47, 495. Jensen, K. A. (1955) Bull. Int. Un. Tuberc.; 25, 89.

Tuberculosis Chemotherapy Centre (1959) Bull. WId. HIth. Org., 21, 51.

Tuberculosis Chemotherapy Centre (1960) Bull. WId. HIth. Org., 23, 535. 